\title{
Enfocando as mulheres da floresta
}

\section{Focusing on jungle women}

\author{
Mariana de Aguiar Ferreira Muaze \\ Mestre em história social da cultura (PUC-RJ) \\ Rua Bambina, 30/404 \\ 22251-050 Rio de Janeiro — RJ Brasil \\ mamuaze@ig.com.br
}

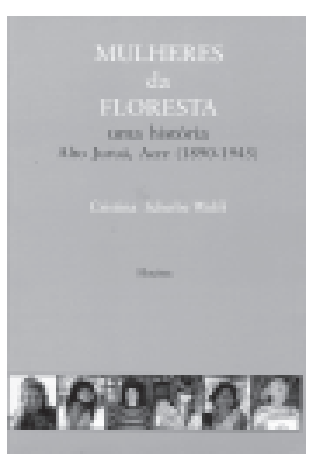

Mulheres da floresta: uma históriaAlto Juruá, Acre (1890-1945)

Cristina Scheibe Wolff

Hucitec, São Paulo, 1999, 291p.
A historiografia costuma descrever a história da Amazônia a partir do surgimento da exploração comercial do látex da seringueira e da grande quantidade de nordestinos que passaram a migrar para a região, principalmente após as secas da década de 1870. Para exemplificar este tipo de abordagem onde a economia da borracha e suas ligações com o mercado externo aparecem com destaque, podemos citar a numerosa obra de Arthur Cesar Ferreira Reis. Entretanto, o livro Mulheres da floresta: uma história - Alto Juruá, Acre (1890-1845) de Cristina Scheibe Wolff aponta em outra direção. A autora critica esta perspectiva, a qual denominou de "fetichização da mercadoria", e ressalta as relações sociais e as experiências vividas por indivíduos, especialmente por mulheres, no cotidiano da floresta.

Para tanto, Cristina Wolff reuniu fontes variadas como, por exemplo, processos civis e criminais (encontrados no Fórum de Cruzeiro do Sul), jornais, relatórios, textos e diários de viajantes (como Constantin Tastevin, Craveiro Costa, Euclides da Cunha, Chandless, Belarmino Mendonça, entre outros). Ao cruzar dados diversos, obteve informações acerca das idades em que os matrimônios se realizavam, seus motivos, a profissão dos envolvidos, as causas de defloramento e assassinato de mulheres, que iluminaram suas conclusões acerca das relações familiares e do cotidiano. Todo este trabalho documental foi somado a um significativo acervo de fontes orais, composto por 26 depoimentos gravados e transcritos, na maioria de mulheres entre sessenta e noventa anos, produzidos em 1995, durante o ano em que a historiadora viveu entre os seringueiros.

Um dos méritos de Cristina Wolff é saber conjugar uma metodologia de história oral, baseada nos relatos de vida, com reflexões acerca da história da Amazônia. O testemunho oral é o núcleo principal de sua investigação. A partir de sua análise vai-se apresentando ao leitor as relações sociais - entre homens e mulheres, entre os poderes público e privado, entre seringueiros e patrões - que fazem parte do cotidiano do seringal. Assim, confrontando os diversos depoimentos, a historiadora recupera as memórias individuais das mulheres e tece considerações sobre a memória coletiva das populações da floresta, que hoje comporta a Reserva Extrativista do Alto Juruá. Nesse sentido, seu trabalho não somente divulga uma memória que, certamente, ficaria restrita às populações que a compartilham, levando-se em consideração que a principal forma de transmissão de conhecimento, nesta sociedade, é a oralidade, mas também a interpreta cunhando um olhar próprio sobre ela. 
O estudo apresentado situa-se entre fins do século XIX, com a constituição dos seringais, e o ano de 1945, quando se encerrou o programa dos governos brasileiro e norte-americano que visava um incremento da produção de borracha para fazer frente às necessidades de guerra das forças aliadas. A pesquisa apresenta esta delimitação temporal porque, no entender de Wolff, a "batalha da borracha" trouxe modificações econômicas que representaram uma recuperação do preço do produto, a abertura de novos seringais e "estradas", nome dado às picadas na floresta ao longo das quais se encontram as seringueiras. Entretanto, não houve mudança significativa nos modos de vida, nos hábitos cotidianos ou nas formas de trabalhar dos seringueiros, que se encontram quase inalterados ainda hoje.

O livro começa pelo período compreendido entre 1890 e 1912, o qual delimita o momento da constituição da sociedade formada a partir da ascensão da borracha e das primeiras levas de migrantes nordestinos que vinham para a Amazônia com o sonho de fazer fortuna. Nesta época, o seringal era uma unidade de produção voltada para o mercado externo, que importava tudo para a sua sobrevivência. O trabalhador tinha obrigação de se dedicar única e exclusivamente à extração do látex, com exceção da caça e da pesca feitas em horários livres. Todo o resto que envolvesse sua subsistência era adquirido no "barracão", que conjugava a residência do patrão, o porto de embarque e desembarque de mercadorias, bem como o depósito das bolas de borracha e o armazém. Localizado estrategicamente nos rios de grande circulação como o Juruá, o "barracão" era abastecido através de vapores, seguindo, depois, em canoas pelos igarapés até os chamados "centros", localidades embrenhadas na mata e perto das "estradas" geradoras de seringa habitadas pelos trabalhadores. Inserido nesta estrutura de comércio, o seringueiro adquiria mercancias a preços exorbitantes e ficava preso ao patrão, pois nunca conseguia "fazer saldo", ou seja alcançar um superávit entre o que ele produzia de borracha e o que devia em mercadorias no barracão do patrão.

Em se tratando desta primeira fase, Cristina Wolff critica a historiografia mais consagrada sobre a Amazônia, a qual insiste em desconsiderar a presença feminina nos momentos de montagem e apogeu dos seringais, ignorando por completo a contribuição e a experiência social das mulheres. Sua proposta é perceber que mesmo sem terem sido concebidas originalmente no esquema de produção idealizado para os seringais, as mulheres e as crianças desempenharam tarefas fundamentais para o funcionamento da "fábrica do seringal". Utilizando como referencial o estudo de Louisse Tilly e Joan Scott (1987) aborda mulher, trabalho e família como categorias inseparáveis. E ressalta o papel das pequenas atividades, como coletar coquinhos para defumar a borracha ou tirar leite de seringueira enquanto o marido vai caçar, para o sustento e a relação da família com o mercado.

Para dar visibilidade às mulheres do Alto Juruá, Cristina Wolff também faz uso do conceito de gênero, recusando conotações biológicas e universalizantes da condição feminina como "sexo" e "papéis sexuais". Dessa forma, sublinha o aspecto relacional entre as mulheres e os homens, ressaltando que a compreensão de qualquer um dos dois somente pode 
existir através de um estudo que não os considere em separado. Em sua perspectiva, o seringal é interpretado como o locus das improvisações acerca destas relações sociais e familiares. Foi no seu cotidiano que seringueiros e seringueiras construíram historicamente um modo de vida que se sustenta na floresta através da convivência cotidiana, de adaptações do modelo nordestino em relação ao novo ambiente e do aprendizado com as populações indígenas.

Sergio Buarque de Holanda (1957), ao estudar a situação da fronteira no Brasil colonial, chamou atenção para o processo de "adaptação" sofrido pelos portugueses ao se depararem com um meio natural diferente do que estavam acostumados. Segundo ele, teria havido uma absorção dos padrões de conduta, técnicas e utensílios dos indígenas e uma diluição da cultura européia durante os primeiros contatos. Contudo, o que veio a se verificar com o passar do tempo foi uma recuperação gradativa do legado ancestral. Cristina Wolff afasta-se da abordagem de Sergio Buarque e afirma que, para o caso da Amazônia, mesmo havendo a permanência de muitos traços da cultura nordestina, a adaptação aos recursos da floresta impediu o resgate da cultura original.

A historiadora defende a idéia de que não houve um "transplante" dos modos de vida do sertão para a Amazônia. Segundo ela, ocorreu o nascimento de um universo cultural original, desenhado através da forte relação do seringueiro com o meio ambiente. Em sua análise, a matriz cultural nordestina aparece em primeiro plano, interpretada como o modelo na construção das relações de gênero e a principal influência no que se refere à constituição familiar nos seringais. Por outro lado, a contribuição dos diversos povos autóctones, cada qual com suas tradições e vinculações culturais, aparece de forma periférica, em sua pesquisa, quando trata da fase de montagem e apogeu do seringal.

Segundo Darcy Ribeiro (1986), até o século XIX, existiam cerca de 28 nações indígenas diferentes na área cultural por ele denominada de JuruáPurus. Entretanto, grande parte destas tribos foi exterminada antes que fosse possivel registrar qualquer documentação sobre seus costumes. Esta aniquilação ocorreu, principalmente, porque muitos povos autóctones resistiram ao enquadramento na "fábrica do seringal", mesmo assim, há evidências de sua incorporação desde os primeiros momentos de vida dos seringais. Como exemplo, vale citar o relato do cientista inglês William Chandless, que percorreu a artéria fluvial do Acre/Purus, entre 1864 e 1865, e afirmou que "os índios hypurinás eram mansos e que trabalhavam durante grande parte do ano com o explorador Manuel Urbano da Encarnação, que se fixara no lugar denominado Canutama, na extração da salsaparrilha" (Castelo Branco, 1947, pp. 129).

No segundo momento histórico abordado, ao contrário de muitos historiadores, Cristina Wolff não compartilha a idéia de que, após o auge da produção borracheira (1890-1912), a região tenha passado por uma baixa populacional e "regredido à mais primitiva forma de subsistência" (p. 98). Seu esforço vai no sentido de demonstrar que essa foi a época mais importante na constituição de uma cultura própria entre os seringueiros. Partindo deste princípio, debruça-se sobre este período de "esquecimento", como ela mesma denomina, e recupera as relações sociais e as adaptações nos modos de vida dos seringueiros, seringueiras e patrões 
em meio à crise do preço da borracha no mercado internacional, iniciada em 1913, quando as colônias inglesas na Ásia, principalmente Ceilão e Malásia, superaram as exportações brasileiras através de uma produção racionalizada da hevea.

Nesta parte do livro, Cristina Wolff demonstra como, diante da nova realidade econômica, buscou-se reorganizar o sistema produtivo, fazendo surgir configurações sociais e relações de gênero diversas das vividas anteriormente. Em seu entender, isso foi possível porque, em primeiro lugar, os seringueiros e seringueiras adquiriram maior autonomia perante os patrões, em virtude da incapacidade dos mesmos de abastecerem os barracões e de garantirem a subsistência nas "colocações". Em segundo lugar, porque era preciso criar uma alternativa de produção que permitisse a independência em relação à demanda do mercado com o intuito de saciar as necessidades básicas dos habitantes da floresta.

O grupo familiar cresceu de importância e se tornou a forma de sobrevivência para aqueles que permaneceram nos seringais. Somente o trabalho de toda família poderia proporcionar um aumento da renda fazendo com que mulheres e crianças, antes voltadas para o trabalho doméstico, conquistassem importância como produtores. Nesta nova conjuntura, as correrias - expedições de captura de índias, contratadas pelos patrões, para serem amansadas e tornarem-se mulheres de seringueiros - assumem a função de trazer mão-de-obra para o seringal. Portanto, para Wolff, o processo de incorporação de nativos tomaria vulto na segunda fase, principalmente no tocante aos núcleos familiares nos quais muitas crianças foram adotadas, mulheres foram "amansadas" e casamentos com seringueiros foram constituídos.

No seu entender, a crise e a desestruturação do sistema produtivo baseado no seringal assumem a conotação de uma profunda transformação social, que proporcionou o nascimento de um modo de vida original: agropecuário, extrativista, voltado para a subsistência e menos dependente do comércio exterior. Estes homens e mulheres diferenciavam-se dos habitantes da fase de montagem da estrutura produtiva pois não possuíam mais aquele estranhamento, característico dos migrantes em seu processo de adaptação à nova vida. Tornaram-se uma "população tradicional", conhecedora da natureza, de seus ciclos e do território que a circunda, ao mesmo tempo que improvisaram um modo de convivência sustentável com a floresta (p. 107).

Dentre as muitas rupturas sociais e econômicas percebidas entre os períodos de apogeu e crise do preço da borracha no mercado internacional, Cristina Wolff destaca a violência como uma continuidade desta sociedade. A seu ver a violência sempre atuou como delineadora das relações sociais. Por seu intermédio pautava-se a autoridade do patrão sobre o seringueiro, do homem sobre a mulher, dos pais sobre os filhos e assim por diante. A violência era encarada como parte integrante da masculinidade, justificando atos extremos, sob pena de desmoralização, em situações de adultério ou desonra, o que popularmente se convencionou denominar de "lavar a honra com sangue".

$\mathrm{Na}$ visão da autora, a situação de fronteira na qual o seringal foi estruturado era propícia à violência. Apesar de o Estado ter reivindicado o monopólio da violência desde 1904, sua legitimidade demora a alcançar 
todas as esferas do poder, perpetuando durante muito tempo a lei de "fazer justiça com as próprias mãos". Isso não significa que não houvesse regras nos seringais, contudo elas não coincidiam com aquelas consideradas modernas e civilizadas nas cidades do centro-sul. Em suas palavras: "A violência marcava a autoridade, o controle, mas também a resistência e a revolta, e assumia o papel de uma linguagem, com a qual muitas coisas eram ditas, e que não se diziam de outra maneira" (p. 195).

Sendo assim, Cristina Wolff, ao reunir em seu estudo as relações de gênero, a história oral e a história social da amazônica, propõe uma abordagem que, sem dúvida, constitui-se num desafio para as novas pesquisas sobre o tema.

\section{REFERÊNCIAS BIBLIOGRÁFICAS}

Buarque de Holanda, Sergio

Castelo Branco, José M. Brandão jul.-set. 1947

Dumas, F. e Muaze, M.

Scott, Joan e Tilly,

Louisse

1987

Ribeiro, Darcy

1986

Sohiet, Rachel

1996
Caminhos e fronteiras. Rio de Janeiro, José Olympio.

'Caminhos do Acre'. Revista do Instituto Histórico e Geográfico Brasileiro, vol. 196.

Os remédios do mato: uma etno-história da saúde e da doença nos vales dos rios Acre e Purus. (mimeo. versão preliminar.)

Woman, work and family

Nova York/ Londres, Methuen.

Índios e a civilização: a integração da população indígena no Brasil moderno. 5ª ed., Petrópolis, Vozes.

'Em busca de novos espaços e relações de gênero'. Revista Acervo, vol. 9, ํㅡㄴ 1/2. 